\title{
Formulasi Pasta Gigi Gel Ekstrak Etanol Bawang Dayak (Eleutherine bulbosa (Mill.) Urb.)
}

\author{
\{Formulation of Bawang Dayak (Eleutherine bulbosa (Mill.) Urb.) Extract \\ into a Gel Toothpaste\}
}

\author{
Husnul Warnida*, Ade Juliannor, Yullia Sukawaty \\ Akademi Farmasi Samarinda
}

\begin{abstract}
Keywords: bawang dayak (Eleutherine bulbosa), Carboxymethyl cellulose, dental caries, gel.

ABSTRACT: Dental caries is a disease of tooth decay that starts from the surface and evolve in the direction of the tooth, beginning with the process of tooth demineralization. Tooth decay is usually caused by the bacterium Streptococcus mutans. Bawang Dayak (Eleutherine bulbosa (Mill.) Urb.) has antibacterial activity due to its compound i.e. flavonoid, fenol, triterpenoid, dan antrakuinon. This study aims to formulate the bawang dayak ethanol extract into a stable gel toothpaste. Bawang dayak ethanol extract 2,5\% was formulated in 5 formulas with varying degree of sorbitol (5 - 50\%) and carboxymethyl cellulose (3 - 7\%). Physical stability of bawang dayak ethanol extract gel toothpastes were evaluated including organoleptic and homogeneity test, $p H$ measurement, viscosity measurement, spreading test, and freeze-thaw cycling test. The result showed bawang dayak ethanol extract gel toothpastes have pH range of 5.50-5.80, spreading area 4.61 - 5.82, viscosity value 17066 - 99877 mPas. Organoleptic and homogeneity in 7 days showed two layers color of gel toothpaste. Consistency test and Freeze-thaw cycling test results showed no change in organoleptic, homogeneity, $\mathrm{pH}$, and viscosity of gel toothpastes.
\end{abstract}

Kata Kunci: bawang dayak (Eleutherine bulbosa), gel, karboksimetil selulosa, karies gigi, pasta gigi.

ABSTRAK: Karies gigi adalah suatu kerusakan gigi yang dimulai dari permukaan dan berkembang ke arah dalam pada gigi, diawali dengan proses demineralisasi gigi. Karies gigi biasanya disebabkan oleh bakteri streptococcus mutans. Bawang dayak (Eleutherine bulbosa (Mill.) Urb) dapat menghambat pertumbuhan bakteri karena mengandung metabolit sekunder seperti flavonoid, fenol, triterpenoid, dan antrakuinon. Penelitian ini bertujuan memformulasikan ekstrak etanol bawang dayak (Eleutherine bulbosa) ke dalam bentuk sediaan pasta gigi gel. Ekstrak bawang tiwai dengan konsentrasi $2,5 \%$ diformulasi menjadi pasta gigi gel dengan variasi sorbitol $5 \%-50 \%$ dan CMC $3 \%-7 \%$. Evaluasi yang dilakukan meliputi organoleptis, homogenitas, $\mathrm{pH}$, viskositas, daya sebar dan freeze-thaw cycling test. Hasil pengamatan organoleptik menunjukan adanya perubahan warna pasta gigi gel menjadi terbentuk 2 lapisan gel. Rentang $\mathrm{pH}$ pasta gigi gel 5,50 - 5,80, rentang uji daya sebar 4,61 - 5,82 cm, rentang viskositas 17066 - 99877 mPas. Hasil sentrifugasi dan cycling test menunjukkan tidak terjadi perubahan organoleptis, homogenitas, $\mathrm{pH}$, dan viskositas pasta gigi gel.

\section{PENDAHULUAN}

Penyakit gigi dan mulut yang paling banyak ditemukan adalah penyakit karies gigi. Karies gigi adalah suatu kerusakan gigi yang dimulai dari permukaan dan berkembang ke arah dalam pada gigi, diawali dengan proses demineralisasi gigi [1]. Proses karies gigi dapat dicegah dengan menggunakan pasta gigi yang mengandung sodium fluoride. Fluoride mencegah karies dengan
${ }^{*}$ Corresponding Author: Husnul Warnida (Akademi Farmasi Samarinda, Jl. Brigjend. Abdul Wahab Sjahranie No. 226, Air Hitam, Samarinda) email: hwarnida@gmail.com
Article History:

Received: 07 Oct 2016 Accepted: 03 Nov 2016

Published: 15 Nov 2016 Available online: 25 Dec 2016 
3 cara yaitu mencegah demineralisasi, peningkatan remineralisasi dan menghambat pertumbuhan bakteri [2]. Bakteri yang menyebabkan karies gigi adalah Streptococcus mutans [3].

Kadar flouride sebanyak 5-10 gram dapat menyebabkan toksisitas [4], tetapi jumlah fluoride dalam pasta gigi cukup rendah sehingga tidak berbahaya jika digunakan dalam jumlah yang tepat [5]. Perlu diperhatikan penggunaan pasta gigi fluoride pada anak di bawah 5 tahun karena dapat tertelan. Menelan fluoride secara terus menerus dapat menyebabkan dental fluorosis [4]. Penggunaan fluoride janggka panjang Salah satu alternatif pengganti flouride adalah bawang dayak. Bawang dayak juga dikenal dengan nama bawang tiwai, bawang sabrang, atau bawang hutan dengan nama latin Eleutherine bulbosa sinonim Eleutherine americana, Eleutherine palmifolia, Eleutherine plicata.

Bawang dayak merupakan tanaman yang memiliki aktivitas antibakteri. Metabolit sekunder pada bawang dayak yang dapat memberikan aktivitas antibakteri di antaranya flavonoid, fenol, glikosida, triterpenoid, dan antrakuinon. Hasil pengujian menunjukkan bahwa ekstrak etanol umbi bawang dayak dapat menghambat pertumbuhan banyak bakteri, di antaranya Bacillus subtilis, Streptococcus pneumoniae, Staphylococcus epidermis, Escherichia coli, Micrococcus luteus, MRSA, Propionibacterium acnes, Samonella typhi, Staphylococcus aureus [6].

Penelitian ini bertujuan memformulasi ekstrak etanol bawang dayak dalam bentuk pasta gigi gel menggunakan Natrium karboksimetilselulosa (CMC) sebagai gelling agent dan sorbitol sebagai humectant. Sorbitol merupakan humectant yang umum digunakan dalam pasta gigi. Sorbitol mempertahankan kadar lembab produk ketika tutup wadah terbuka. Sorbitol juga memberikan rasa manis tanpa menambah risiko kerusakan gigi. CMC digunakan sebagai bahan pengikat berupa gelling agent (senyawa pembentuk gel) yang berfungsi untuk memberikan bentuk semisolid yang stabil.

\section{METODE PENELITIAN}

\section{Alat dan Bahan}

Alat yang digunakan adalah alat gelas $\left(\right.$ Pyrex $\left.^{\circledR}\right)$, jangka sorong (Krisbow), magnetic stirer, mortar dan stamper, pengayak mesh 40, pH meter, rotary evaporator (IKA), seperangkat alat maserator, termometer, timbangan digital $\left(\mathrm{OHAUS}^{\circledR}\right)$, vacuum rotary, viscometer VP 1000.

Bahan yang digunakan adalah air suling, bawang dayak, etanol 70\%, mentol (kualitas farmasetis), minyak permen (kualitas farmasetis), natrium CMC (kualitas farmasetis), natrium benzoat (kualitas farmasetis), sorbitol (kualitas farmasetis).

\section{Prosedur Kerja}

1. Pengolahan Sampel

Umbi bawang dayak yang diperoleh dari petani di kelurahan Air Hitam Kota Samarinda dibersihkan, dirajang, dan dikeringkan selama 1 minggu. Selanjutnya dihaluskan menjadi serbuk dan diayak dengan pengayak nomor 40 .

\section{Ekstraksi Sampel}

Sebanyak 300 gram serbuk kering umbi bawang dayak dimaserasi dengan pelarut etanol 70\%. Direndam selama 6 jam pertama sambil sesekali diaduk, kemudian didiamkan selama 18 jam. Dipisahkan maserat dengan cara disaring. Ampas dimaserasi kembali dengan etanol 70\% menggunakan prosedur yang sama sebanyak 3 kali. Seluruh maserat digabung dan dipekatkan dengan bantuan alat rotary evaporator pada suhu $50^{\circ} \mathrm{C}$ sampai diperoleh ekstrak kental [7]. Selanjutnya disimpan dalam desikator.

\section{Formulasi Pasta Gigi Gel}


Fomula pasta gigi gel ekstrak etanol bawang dayak disajikan di Tabel 1. CMC didispersikan dalam air suling. Menthol dilarutkan dalam etanol. Natrium benzoat dilarutkan dalam air suling. Ekstrak diencerkan dengan etanol dan ditambah sorbitol dan larutan mentol. Ditambahkan dispersi CMC dan larutan natrium benzoat. Diaduk sampai homogen. Ditambahkan peppermint oil.

\section{Evaluasi Stabilitas Gel}

\section{Uji Organoleptis}

Dilakukan pengamatan visual terhadap bau, warna, dan bentuk gel selama 7 hari. Gel biasanya jernih dengan konsistensi setengah padat.

\section{Pemeriksaan homogenitas}

Pengujian homogenitas dilakukan dengan mengoleskan zat yang akan diuji pada sekeping kaca atau bahan lain yang cocok harus menunjukkan susunan yang homogen dan tidak menunjukkan butiran kasar.

\section{Pengukuran Daya Sebar}

Sampel seberat 0,5 $\mathrm{g}$ diletakkan di atas kaca dan ditunggu selama 1 menit. Diameter sebar sampel diukur. Selanjutnya ditambah $150 \mathrm{~g}$ beban dan didiamkan selama 1 menit lalu diukur diameter yang konstan.
4. Pengukuran $\mathrm{pH}$

Dilakukan pengukuran $\mathrm{pH}$ gel menggunakan pH meter yang telah dikalibrasi pada $\mathrm{pH} 4,00$ dan pH 6,86 .

\section{Pengukuran Viskositas}

Sebanyak $100 \mathrm{ml}$ gel dimasukkan ke dalam gelas piala $250 \mathrm{ml}$ kemudian viskositasnya diukur dengan Viscometer menggunakan spindle dan kecepatan yang sesuai.

\section{Pengujian Stabilitas dipercepat}

Gel disentrifugasi selama 5 jam dengan kecepatan $3800 \mathrm{rpm}$. Tidak boleh terjadi perubahan bentuk dan pemisahan fase.

\section{Pengujian Freeze-thaw cycling}

Gel diletakkan pada suhu $\left(4 \pm 2^{\circ} \mathrm{C}\right)$ selama 24 jam dilanjutkan dengan meletakkan sampel sediaan $\left(4 \pm 2^{\circ} \mathrm{C}\right)$ selama 24 jam (1 siklus), pengujian dilakukan sebanyak 3 siklus dan diamati perubahan fisik dari sediaan pada awal dan akhir siklus yang meliputi organoleptis, viskositas dan $\mathrm{pH}[8]$.

\section{HASIL DAN DISKUSI}

Evaluasi Sifat Fisik Gel

1. Pengamatan Organoleptis dan Homogenitas Gel

Tabel 1. Formula Pasta Gigi Gel Ekstrak Etanol Bawang Dayak

\begin{tabular}{|c|c|c|c|c|c|c|}
\hline \multirow{2}{*}{ Nama Bahan } & \multirow{2}{*}{ Fungsi } & \multicolumn{5}{|c|}{ Formula (\%) } \\
\hline & & $A$ & $B$ & $C$ & $D$ & $E$ \\
\hline Ekstrak etanol bawang dayak & Bahan aktif & 2,5 & 2,5 & 2.5 & 2,5 & 2,5 \\
\hline $\mathrm{CMC}$ & Gelling agent & 3 & 4 & 5 & 6 & 7 \\
\hline Sorbitol & Humectants & 50 & 40 & 20 & 10 & 5 \\
\hline Mentol & Pengaroma & 0,5 & 0,5 & 0,5 & 0,5 & 0,5 \\
\hline Natrium benzoat & Pengawet & 0,5 & 0,5 & 0,5 & 0,5 & 0,5 \\
\hline Peppermint oil & Pengaroma & 0,3 & 0,3 & 0,3 & 0,3 & 0,3 \\
\hline Etanol 95\% & Pelarut & 3 & 3 & 3 & 3 & 3 \\
\hline Air suling ad & Pelarut & 100 & 100 & 100 & 100 & 100 \\
\hline
\end{tabular}


Tabel 2. Mutu Fisik Pasta Gigi Gel Ekstrak Etanol Bawang Dayak

\begin{tabular}{|c|c|c|c|c|c|}
\hline \multirow{2}{*}{ Formula } & \multirow{2}{*}{ Parameter } & \multicolumn{3}{|c|}{ Organoleptis dan Homogenitas Gel } & \multirow[b]{2}{*}{ Hari Ke-21 } \\
\hline & & Hari Ke-1 & Hari Ke-7 & Hari Ke-14 & \\
\hline \multirow{4}{*}{$\begin{array}{l}\text { Formula } \\
\text { A }\end{array}$} & Warna & Merah bata & Merah bata kekuningan & Merah bata kekuningan & Merah bata kekuningan \\
\hline & Bau & Mint & Mint & Mint & Mint \\
\hline & Rasa & Pedas & Pedas & Pedas & Pedas \\
\hline & Homogenitas & Homogen & Tidak homogen & Tidak homogen & Tidak homogen \\
\hline \multirow{4}{*}{$\begin{array}{l}\text { Formula } \\
\text { B }\end{array}$} & Warna & Merah bata & Merah bata kekuningan & Merah bata kekuningan & Merah bata kekuningan \\
\hline & $\mathrm{Bau}$ & Mint & Mint & Mint & Mint \\
\hline & Rasa & Pedas & Pedas & Pedas & Pedas \\
\hline & Homogenitas & Homogen & Tidak homogen & Tidak homogen & Tidak homogen \\
\hline \multirow{4}{*}{$\begin{array}{l}\text { Formula } \\
\text { C }\end{array}$} & Warna & Merah bata & Merah bata kekuningan & Merah bata kekuningan & Merah bata kekuningan \\
\hline & $\mathrm{Bau}$ & Mint & Mint & Mint & Mint \\
\hline & Rasa & Pedas & Pedas & Pedas & Pedas \\
\hline & Homogenitas & Homogen & Tidak homogen & Tidak homogen & Tidak homogen \\
\hline \multirow{4}{*}{$\begin{array}{l}\text { Formula } \\
\text { D }\end{array}$} & Warna & Merah bata & Merah bata kekuningan & Merah bata kekuningan & Merah bata kekuningan \\
\hline & $\mathrm{Bau}$ & Mint & Mint & Mint & Mint \\
\hline & Rasa & Pedas & Pedas & Pedas & Pedas \\
\hline & Homogenitas & Homogen & Tidak homogen & Tidak homogen & Tidak homogen \\
\hline \multirow{4}{*}{$\begin{array}{l}\text { Formula } \\
\text { E }\end{array}$} & Warna & Merah bata & Merah bata kekuningan & Merah bata kekuningan & Merah bata kekuningan \\
\hline & $\mathrm{Bau}$ & Mint & Mint & Mint & Mint \\
\hline & Rasa & Pedas & Pedas & Pedas & Pedas \\
\hline & Homogenitas & Homogen & Tidak homogen & Tidak homogen & Tidak homogen \\
\hline
\end{tabular}

Keterangan:

Formula A : konsentrasi CMC 3\% dan Sorbitol 50\%

Formula B : konsentrasi CMC 4\% dan Sorbitol 40\%

Formula C : konsentrasi CMC 5\% dan Sorbitol 20\%

Formula D : konsentrasi CMC 6\% dan Sorbitol 10\%

Formula E : konsentrasi CMC 7\% dan Sorbitol 5\%

Hasil pengamatan organoleptis dan homogenitas pasta gigi gel ekstrak etanol bawang dayak dapat dilihat di Tabel 2 .

Hasil pengamatan organoleptis pada hari ke-7 menunjukkan perubahan bentuk dan warna dari semua formula. Pada hari ke-1 gel formula A, B, C, D, dan E berwarna merah bata sedangkan pada hari ke-7 warna gel berubah menjadi merah bata kekuningan dan membentuk 2 lapisan warna. Perubahan warna gel menjadi 2 lapisan disebabkan oleh migrasi ekstrak bawang dayak dari lapisan atas ke lapisan bawah, sehingga warna gel di bagian atas menjadi lebih terang. Perpindahan ini terjadi karena ekstrak etanol bawang dayak tidak dalam keadaan terlarut, melainkan terdispersi dalam gel. Bobot jenis ekstrak yang lebih besar dari air membuat ekstrak turun ke dasar gel.

Sediaan gel dikatakan homogen bila terdapat persamaan warna yang merata dan tidak adanya partikel atau bahan kasar yang dapat diraba [9]. Persyaratan homogenitas gel dimaksudkan agar bahan aktif dalam gel terdistribusi merata. Selain itu agar gel tidak mengiritasi ketika dioleskan di kulit. Pasta gigi gel tidak mengalami pemisahan antara padatan dan air. Ketidakhomogenan yang dimaksud adalah gradasi warna pada gel.

\section{Pengukuran pH Gel}

Hasil pengukuran $\mathrm{pH}$ pasta gigi gel ekstrak etanol bawang dayak dapat dilihat di Tabel 3. 
Tabel 3. Nilai pH Gel Ekstrak Etanol Bawang Dayak

\begin{tabular}{|c|c|c|c|c|}
\hline \multirow{2}{*}{ Formula Gel } & & \multicolumn{2}{|c|}{$p H$ Gel } & \\
\hline & Hari ke-1 & Hari ke-7 & Hari ke-14 & Hari ke-21 \\
\hline Formula A & 5,74 & 6,10 & 6,17 & 6,18 \\
\hline Formula B & 5,50 & 6,08 & 6,15 & 6,19 \\
\hline Formula C & 5,73 & 6,20 & 6,29 & 6,30 \\
\hline Formula D & 5,80 & 6,33 & 6,36 & 6,39 \\
\hline Formula E & 5,77 & 6,44 & 6,45 & 6,50 \\
\hline
\end{tabular}

Tabel 4. Daya Sebar Gel Ekstrak Etanol Bawang Dayak

\begin{tabular}{|c|c|c|c|c|}
\hline \multirow{2}{*}{ Formula Gel } & \multicolumn{4}{|c|}{ Diameter sebar $(\mathrm{cm})$ dengan beban $150 \mathrm{~g}$} \\
\hline & Hari ke-1 & Hari ke-7 & Hari ke-14 & Hari ke-21 \\
\hline Formula A & 5,82 & 5,57 & 5,83 & 6,24 \\
\hline Formula B & 5,13 & 5,35 & 5,56 & 5,72 \\
\hline Formula C & 5,13 & 5,46 & 5,52 & 5,60 \\
\hline Formula D & 5,06 & 5,17 & 5,28 & 5,45 \\
\hline Formula E & 4,61 & 4,82 & 4,71 & 4,89 \\
\hline
\end{tabular}

Keterangan:

Formula A : konsentrasi CMC 3\% dan Sorbitol 50\%

Formula B : konsentrasi CMC 4\% dan Sorbitol $40 \%$

Formula C : konsentrasi CMC 5\% dan Sorbitol 20\%

Formula D : konsentrasi CMC 6\% dan Sorbitol 10\%

Formula E : konsentrasi CMC 7\% dan Sorbitol 5\%

Pengukuran pH merupakan parameter fisikokimia yang penting pada sediaan topikal karena $\mathrm{pH}$ berkaitan dengan efektivitas zat aktif, stabilitas zat aktif dan sediaan, serta kenyamanan di kulit sewaktu digunakan. Nilai pH yang terlalu asam dapat mengakibatkan iritasi sedangkan pH yang terlalu basa dapat menyebabkan kulit bersisik. Dari hasil pengukuran $\mathrm{pH}$ pada hari pertama terlihat bahwa sediaan gel ekstrak etanol bawang dayak berkisar antara 5,50 - 5,80. Nilai pH ini sesuai dengan persyaratan mutu pasta gigi gel pada SNI 12-3524-1995 yaitu 4,5 - 10,5.

\section{Pengukuran Daya Sebar Gel}

Hasil pengukuran daya sebar pasta gigi gel ekstrak etanol bawang dayak dapat dilihat di Tabel 4.

Uji daya sebar sediaan gel dimaksudkan untuk mengetahui kemampuan menyebar gel saat dioleskan pada kulit. Kemampuan menyebar adalah karakteristik penting dalam formulasi karena mempengaruhi transfer bahan aktif pada daerah target dalam dosis yang tepat, kemudahan penggunaan, tekanan yang diperlukan agar dapat keluar dari kemasan, dan penerimaan oleh konsumen [10]. Dari hasil pengukuran diameter daya sebar, sediaan gel ekstrak etanol bawang dayak formula $\mathrm{E}$ tidak memenuhi persyaratan daya sebar yaitu 5 sampai $7 \mathrm{~cm}$. Hal ini disebabkan jumlah CMC yang tinggi dalam formula E. Semakin besar jumlah CMC, semakin sedikit penyebaran gel.

\section{Pengukuran Viskositas}

Hasil pengukuran viskositas pasta gigi gel ekstrak etanol bawang dayak dapat dilihat di Tabel 5.

Viskositas formula dipengaruhi oleh konsentrasi CMC dan sorbitol. Viskositas formula A selama penyimpanan 3 minggu berkisar antara 17066-19422 mpas. Formula A memiliki konsistensi yang encer sehingga pada saat dikeluarkan dari tube tidak membentuk gel yang 
Tabel 5. Viskositas Gel Ekstrak Etanol Bawang Dayak

\begin{tabular}{|c|c|c|c|c|}
\hline \multirow{2}{*}{ Formula Gel } & & \multicolumn{3}{|c|}{ Viskositas gel pada $20 \mathrm{rpm}$} \\
\hline & Hari ke-1 & Hari ke-7 & Hari ke-14 & Hari ke-21 \\
\hline Formula A & 17066 & 18055 & 18788 & 19422 \\
\hline Formula B & 33222 & 35210 & 37266 & 38500 \\
\hline Formula C & 48955 & 50088 & 56388 & 58333 \\
\hline Formula D & 78065 & 80955 & 86922 & 89700 \\
\hline Formula E & 99877 & 101944 & 106754 & 107826 \\
\hline
\end{tabular}

Tabel 6. Hasil Pengamatan Organoleptis Gel selama 3 Siklus

\begin{tabular}{|c|c|c|c|c|}
\hline \multirow{2}{*}{ Formula Gel } & \multicolumn{4}{|c|}{ Pengamatan Organoleptis } \\
\hline & Warna & Aroma & Rasa & Konsistensi \\
\hline Formula A & Merah bata, terbentuk 2 lapisan warna & Mint & Pedas & Tidak ada pemisahan \\
\hline Formula B & Merah bata, terbentuk 2 lapisan warna & Mint & Pedas & Tidak ada pemisahan \\
\hline Formula C & Merah bata, terbentuk 2 lapisan warna & Mint & Pedas & Tidak ada pemisahan \\
\hline Formula D & Merah bata, terbentuk 2 lapisan warna & Mint & Pedas & Tidak ada pemisahan \\
\hline Formula E & Merah bata, terbentuk 2 lapisan warna & Mint & Pedas & Tidak ada pemisahan \\
\hline
\end{tabular}

Tabel 7. Hasil Pengukuran pH Gel selama 3 Siklus

\begin{tabular}{|c|c|c|c|}
\hline \multirow{2}{*}{ Formula Gel } & & $p H$ Gel & \\
\hline & Siklus 1 & Siklus 2 & Siklus 3 \\
\hline Formula A & 6,02 & 6,04 & 6,08 \\
\hline Formula B & 6,02 & 6,08 & 6,12 \\
\hline Formula C & 6,08 & 6,10 & 6,11 \\
\hline Formula D & 6,14 & 6,16 & 6,22 \\
\hline Formula E & 6,15 & 6,18 & 6,21 \\
\hline
\end{tabular}

Keterangan:

Formula A : konsentrasi CMC 3\% dan Sorbitol 50\%

Formula B : konsentrasi CMC $4 \%$ dan Sorbitol $40 \%$

Formula C : konsentrasi CMC 5\% dan Sorbitol 20\%

Formula D : konsentrasi CMC 6\% dan Sorbitol 10\%

Formula E : konsentrasi CMC 7\% dan Sorbitol 5\%

utuh di atas sikat gigi. Nilai viskositas formula B berkisar antara 33222-38500 mpas, viskositas formula C antara 48955-58333 mpas, dan viskositas formula D antara 78065-89700 mpas. Formula B, $\mathrm{C}$, dan D membentuk gel yang konsisten pada sikat gigi [11], sehingga ketiga formula memenuhi persyaratan pasta gigi gel. Formula E memiliki nilai viskositas yang paling besar berkisar antara 99877-107826 mpas. Formula E memiliki konsistensi yang keras, sehingga saat dikeluarkan dari tube tidak menyebar sempurna di atas sikat gigi.

\section{Pengamatan Freeze-thaw cycling}

Hasil pengamatan freeze-thaw cycling selama 3 siklus pada pasta gigi gel ekstrak etanol bawang dayak meliputi pengamatan organoleptis, pengukuran $\mathrm{pH}$, dan pengukuran viskositas dapat dilihat di Tabel 6, Tabel 7, dan Tabel 8.

Uji freeze-thaw cycling dilakukan untuk melihat pengaruh suhu terhadap gel selama penyimpanan pada dua suhu yang berbeda yaitu kondisi beku (frezee) pada suhu $4^{\circ} \mathrm{C}$ dan meleleh (thaw) pada suhu $45^{\circ} \mathrm{C}$. Pengamatan organoleptis pada siklus pertama, kedua dan ketiga tidak menunjukkan 
Tabel 8. Hasil Pengukuran Viskositas Gel selama 3 Siklus

\begin{tabular}{|c|c|c|c|}
\hline \multirow{2}{*}{ Formula Gel } & \multicolumn{3}{|c|}{ Viskositas Gel (mPas) } \\
\hline & Siklus 1 & Siklus 2 & Siklus 3 \\
\hline Formula A & 12167 & 12566 & 12900 \\
\hline Formula B & 22233 & 22266 & 22600 \\
\hline Formula C & 29166 & 30833 & 31800 \\
\hline Formula D & 48067 & 48433 & 49133 \\
\hline Formula E & 59700 & 60167 & 69333 \\
\hline
\end{tabular}

Tabel 9. Hasil Pengamatan Stabilitas Dipercepat

\begin{tabular}{|c|c|c|}
\hline \multirow{2}{*}{ Formula Gel } & \multicolumn{2}{|c|}{ Konsistensi Gel } \\
\hline & Sebelum & Sesudah \\
\hline Formula A & Tidak terpisah & Tidak terpisah \\
\hline Formula B & Tidak terpisah & Tidak terpisah \\
\hline Formula C & Tidak terpisah & Tidak terpisah \\
\hline Formula D & Tidak terpisah & Tidak terpisah \\
\hline Formula $\mathrm{E}$ & Tidak terpisah & Tidak terpisah \\
\hline
\end{tabular}

Keterangan:

Formula A : konsentrasi CMC 3\% dan Sorbitol 50\%

Formula B : konsentrasi CMC 4\% dan Sorbitol 40\%

Formula C : konsentrasi CMC 5\% dan Sorbitol 20\%

Formula D : konsentrasi CMC 6\% dan Sorbitol 10\%

Formula E : konsentrasi CMC 7\% dan Sorbitol 5\%

perubahan fisik dan pemisahan fase antara matriks gel dan air pada semua formula. Pengukuran $\mathrm{pH}$ dan viskositas menunjukan kenaikan selama perlakukan 3 siklus, tetapi masih dalam batas yang dipersyaratkan.

\section{Pengamatan Stabilitas dipercepat}

Hasil pengamatan stabilitas dipercepat dari pasta gigi gel ekstrak etanol bawang dayak dapat dilihat di Tabel 9.

Uji stabilitas dipercepat dilakukan dengan cara mekanik menggunakan sentrifugator. Gel disentrifugasi pada kecepatan 3800 rpm selama 5 jam. Setelah 5 jam tidak terlihat perubahan bentuk, bau, warna, dan homogenitas dari pasta gigi gel ekstrak etanol bawang dayak. Hal ini berarti konsistensi pasta gigi gel ekstrak etanol bawang dayak stabil dalam penyimpanan.

\section{KESIMPULAN}

Berdasarkan hasil uji stabilitas fisik gel semua formula mengalami perubahan warna pada penyimpanan hari ke-7. Rentang $\mathrm{pH}$ formula pasta gigi gel antara 5,50-5,80, rentang daya sebar formula pasta gigi gel antara 4,61-5,82 cm, rentang viskositas formula pasta gigi gel antara 1706699877 mpas. Uji stabilitas dipercepat dengan cara sentrifugasi dan freeze-thaw cycling test menunjukkan tidak terjadi perubahan organoleptis dan homogenitas pasta gigi gel.

\section{DAFTAR PUSTAKA}

1. Storehagen, S., Ose N., and Midha, S. (2003). Dentrifices and Mouthwash ingredients and their use. Oslo: Universiteteti Oslo.

2. Lynch, R.J.M., Navada, R., Walia, R. (2004). Low-levels of fluoride in plaque and saliva and their effects on the demineralization and reminalisation of enamel: rule of fluoride toothpaste. International Dental Journal, 54(55), 303-309. 
3. Forssten, D.S., Bjorklund, M., Ouwehand, a.C., (2010). Streptococcus mutans, caries and simulation models. Nutrients, 2(3), 290-298.

4. Heifetz, B.S., Horowitz, H.S., Meyers, R.J.Li, S. (1987). Evaluation of the comparative effectiveness of fluoride mouthrinsing, fluoride tablets, and both procedures in combination: interim findings after two years. Pediatric Dentistry, 9(2), 121-125.

5. Marinho, V.C, Higgins, J.P.T., Logan, S., Sheiham, A. (2002). Fluoride toothpaste for preventing dental caries in children and adolescents. Cochrane Database of Syst. Rev., 2002(3).

6. Mierza, V., Suryanto, D., \& Nasution, P.M. (2011). Skrining fitokimia dan uji efek antibakteri ekstrak etanol umbi bawang sabrang (Eleutherine palmofolia Merr.). Prosiding Seminar Nasional. Universitas Sumatera Utara. Medan.

7. Depkes RI. (2008). Farmakope Herbal. Jakarta: Departemen Kesehatan RI
8. Djajadisastra, J., Munlim, A., Dessy, N.P. (2009). Formulasi Gel Topikal dari Ekstrak Nerii Folium dalam Sediaan Anti Jerawat. Jurnal Farmasi Indonesia. 4 (4).

9. Setyaningrum, N.L. (2013). Pengaruh Variasi Kadar Basis HPMC dalam Sediaan Gel Ekstrak Etanolik Bunga Kembang Sepatu (Hibiscus rosa-sinensis L.) terhadap Sifat Fisik dan Daya Antibakteri Pada Staphylococcus aureus. Naskah Publikasi. Universitas Muhammadiyah Surakarta.

10. Garg, A., Aggarwal, D., Garg, S., Sigla, A.K. (2002). Spreading of Semisolid Formulation: An Update. Pharmaceutical Technology. September 2002: 84-102.

11. Lida, A. D., Fith, K. N., Onny, I. 2010. Penggunaan Na-CMC Gelingg Agent Dalam Formula Pasta Gigi Ekstrak Etanol 70\% Daun Jambu Biji (Psidium guajava L.). Farmasains, 1 (1). 